\section{Bond-centred end-of-life care: mindset, challenges and protocols}

\section{Diane James}

\section{UNDERSTANDING BOND-CENTRED END-OF-LIFE CARE}

Bond-centred end-of-life care is the systematic approach to dealing with the clients' (pet owners') needs, as well as treating the medical needs of the pet. This approach is often seen in animal hospices, which are now starting to appear in the UK, also veterinary surgeons who provide palliative care in and outside of the (bond-centred) practice. It is about how we meet the needs of clients, in relation to pet loss, and providing them with the support that they require emotionally, especially when dealing with grief.

\section{WHAT WE NEED TO LOOK AT AND BE AWARE OF WITH BOND-CENTRED END-OF-LIFE CARE}

Working with clients and pets in this way, means that you need to be aware of the challenges of the role, the mindset of the team or individuals, and ensuring you keep within the boundaries and protocol of the practice. It is important to have these boundaries in place, this will ensure you know how to deliver the right level of service and expectation, without crossing these boundaries. Never underestimate working with a client in such an emotive environment. It is sensible for all parties involved to have an awareness of the level of expectation and support, not only for the client, but also for the team or persons involved in the care.

\section{OUTCOME}

Ideally the outcome will always be in the best interest of the pet, as well as the owner. This can be achieved by having a consistent and well managed approach, whilst remaining supportive, communicative and emotionally resilient.

\section{KEY LEARNING OBJECTIVES}

- Explain what bond-centred end-of-life care is

- List the challenges to the team

- List the consequences to the client

\section{MULTIPLE CHOICE QUESTIONS}

1. What does the term end-of-life care refer to?

(A) The provision of palliative care

(B) The euthanasia of the animal (if required)

(C) A terminal illness, with a short life expectancy

(D) All of the above

2. A client is very emotional, crying and distraught. How do you handle this?
(A) Let them have space, listen when they are ready
(B) Hug them, be affectionate
(C) Ignore them and feel slightly embarrassed
(D) Go and make yourself a cup of tea

3. What is the key to a well managed approach to bond-centred end-of-life care?
(A) Clear concise communication
(B) Understanding the need for resilience
(C) Awareness of no one size fits all
(D) All of the above

\section{The client journey: supporting the client before and after the last appointment}

\section{Diane James}

The right support during the client journey is vital to client retention and the reputation of the practice. The need to support a client starts from the first point of contact, be that telephone or face to face. That is why it is important to ensure every member of the team is trained and has an empathetic way of working. There are many elements which go to make up the client's journey. Whilst a number of these elements can be the same for one and all, it is vital to realize that with grief, everyone is individual. So, there are steps that can be put in place, to make sure you offer good support. There is also the need to recognize that not all your team can be compassionate and have the full skill set to support the client.

We often hear how good the support was before and during the loss of an animal, but that the client aftercare was non-existent. Getting it right can include elements that are fairly simple, such as sign posting to other organizations. Even the smallest act of sending a bereavement card can go one of two ways, be seen as the most caring and heartfelt event, or, if not handled correctly, be the deciding factor in losing the client.

Often people can feel uncomfortable dealing with loss and grief, both before and after the event. It is important to understand the different types of grief, and learn that often the smallest of acts can make the biggest difference. Even if you don't have a purpose-built environment, you can get it right. We will look at ways to ensure we support the client, no matter what. 


\section{Understanding empathy in association with Blue Cross}

\section{KEY LEARNING OBJECTIVES}

- Understand what a supporting role is

- Be able to define a number of different types of grief

- Identify ways to implement the support

\section{MULTIPLE CHOICE QUESTIONS}

1. What does the term complicated grief refer to?

(A) The client is uncertain of what treatment is required

(B) The illness is more complicated than the client realizes

(C) Its all too complicated, to understand

(D) A combination of difficult circumstances
2. Which of these, after a loss, can cause a client to leave your practice?

(A) A vaccination reminder is sent out

(B) A message to collect the ashes is left on their answer machine

(C) A card is sent with a preprinted message in it

(D) All of the above

3. Why should all members of the team receive training in pet bereavement?

(A) Helps them to understand the grief and loss of a client

(B) Helps them with their own resilience

(C) Provides good customer care and service

(D) All of the above 